\title{
HE AWA WHIRIA (BRAIDED RIVERS)
}

\section{David Hursthouse}

With gratitude to Kelli Te Maihāroa, Steve Henry, Alexa Forbes and Tuia Learning Environment for their ongoing support and mentorship

"The seed I would like to plant in your heart is a vision of Aotearoa where all our people can live together in harmony. We must learn from each other and share the wisdom from each culture. We need the knowledge the Päkehā brings from all over the world as well as the sense of belonging and whakapapa of the Māori. The separate paths our people have trod can unite in a highway to the future that is built on the best of both. Māori and Pākehā, alone and divided, cannot build a secure and happy future for Aotearoa. We have to appreciate the best in each other and at the highest levels share our knowledge and vision. Look back to appreciate the past, but look forward to advance what is missing."

Dame Whina Cooper

Lived experience and prior inquiry has enabled me to see that humanity faces a web of extreme socio-ecological crises. While many strategies exist for dealing with these crises, I believe that it will be exceptionally difficult to realise any of them without significant changes to the way we organise and collaborate socially.

To contribute to this shift in social collaboration, I have been involved in an inquiry that spans a Graduate Diploma in Professional Practice (GradDipProfPrac, completed March 2019), and is now continuing across a Doctorate in Professional Practice (DProfPrac). This autoethnographic exploration is deeply subjective, personal and collaborative. It loops through time, spreads across cultures, intertwines with my whakapapa, emerges from a burning fire in my heart, and is resolutely focused on our collective survival. I am sharing a glimpse of this inquiry here.

Organisational theory is deeply, oppressively colonised. Dominant modes of organisation today stem from industrial colonial worldviews that subdivide the world, do not allow for diverse cultural ways of knowing, and are models of behaviour that divorce us socio-ecological systems.

\section{Dominant organisation patterns cause degenerative consequences, jeopardising the survival of the human family.}

I suggest that in peeling back the layers of colonisation together and in re-learning from the life-creating processes of the world around us, we have a beautiful opportunity to evolve our organisational patterns to have a healing and regenerative impact on socio-ecological systems.

I am exploring the weaving of Māori and Pākehā ways of knowing in Aotearoa New Zealand - pre-colonisation, colonised and decolonising. Where similarities emerge in between these ways of knowing, I am exploring what potential those similarities hold for cultural healing and decolonised organisation in Aotearoa New Zealand. 
I seek to honor the organisational concepts of te ao Māori as "... a combination that spans the past, the present and the future, within which Māori strive to achieve the values, principles and ideals that exist within our culture ..." (Kent, 20 I I, p. 36). In doing so, I seek to express this way of knowing as the equally valid, authentic, important, contemporary and relevant ecosystem of ideas that it is.

I suggest that all patterns of social organisation have their genesis in cultural creation stories - sometimes consciously, often unconsciously. I will suggest that in allowing ourselves to hold our own stories loosely and listen openly to the stories of others, we allow ourselves to move beyond the parameters of our cultural conditioning.

At it's core, this inquiry is an expression of process: of my own surrendering to different ways of knowing and the active decolonisation of my heartmind.

Theories of organisation in an academic context are, almost without fail, rooted in the Western worldview. "The Western body of knowledge has regularly been promoted globally as the singular world consciousness, being presented as all-encompassing and impartial (Abbott \& Durie, 1987)." (Macfarlane et al, 2015, p. 59). The predominant discourse around organisation is framed by perception that evolved in Western conceptual spaces.

"For too long western philosophy has occupied center stage, and has maintained itself there, in part, by proposing a dichotomous relationship of the privileged western "progressive" self to the "backward" perspective of non-western, indigenous knowledge systems."

(Wilmer, 1999, p. 1)

Through the process of colonisation, nations of the West have imposed their way of knowing on many diverse cultural groups - including Māori in Aotearoa.

"[Māori] colonial experience has been one of denial. Denial of our reo, denial of our tikanga, denial of our whenua, denial of our taonga, denial of our whakapapa. Colonial forces have attempted to deny us all of those things that contribute to our notions of who we are and where we fit in the world ... Decolonisation then includes a peeling back of the layers. Layer by layer. Constantly reflecting on what we find."

(Pihama, 200I, p. 288).

Colonial ways of knowing have been so oppressive that forms of social organisation within Māori communities are forcibly shaped by colonial structures, ideas, processes and cultural norms. These Pākehā ideologies can strip Māori of identity and meaning.

"A dynamic interaction of indigenous and non-indigenous elements of governance and culture is the reality of Māori organisations and people today within society. This dynamic represents... the fullest level of Māori cultural expression of traditional concepts allowed, within social, legal, organisational and environmental constraints of what is an era of more subtle colonialism".

(Kent, 201 I, p. 38).

Aotearoa New Zealand is today a society guided by deeply embedded "ethnocentric and phallocentric views" (Murphy, 20 I I, p. 15). The nation exists on a foundation of racist oppression, and is often moderated by patriarchy and neo-liberal capitalism.

None of that is Māori. 
"Western knowledge has ... colonised the theoretical space of indigenous knowledge deeming it as inferior ... However, it is overly simplistic to think of non-scientific knowledge as inferior knowledge. Indigenous knowledge, which contains values, concepts and wisdom, has enabled longterm survival".

(Kent, 201 I, p. 53)

"Science can open a fire hose of information, but it leaves us with not a drop of wisdom. We need both to survive".

(Brock, 2017, p. 55).

While the Western world is afraid to acknowledge "that science is just as arbitrary and incomplete an epistemology [way of knowing] as the modes that came before it," (Brock, 2017, p. 54) the Euro-scientific method continues to be supported by the weight of institutionalised Western society as having a "monopoly on truth" (Brock, 20 I7, p. 54).

"There are multitudes of ways of knowing. Each one, in its own way, gives an important perspective on 'truth'... As we seek to pick up the pieces from our present moment's epistemic fracturing, we are called to focus on connections rather than divisions, reweaving the tapestry of meaning into something more diverse - and therefore stronger - than any one way of knowing on its own."

(Brock, 2017, p. 55)

If we are to come close to the ecologically synergetic social systems that we need to survive and thrive in an uncertain future, the privileging of one way of knowing must end.

In my GradDipProfPrac I explored life-creating organisational processes and suggested that reinhabiting these patterns is not possible without breaking down the hegemony of the Western basket of knowledge. Pākehā are only just beginning to understand living concepts that have forever been a part of Māori awareness - science is only just starting to 'prove' what has been validated by indigenous knowledge for millenia. The Māori kete of knowledge can remind Pākehā of wisdom-based learning and what it means to embody kaitiakitanga.

"All indigenous peoples have a tradition of unity with the environment and the tradition is reflected in song, custom, subsistence, approaches to healing, birthing, and the rituals associated with death. The defining characteristic of indigenous peoples is therefore not necessarily premised on colonisation or sovereignty or a prior claim to settlement, but on a longstanding relationship with land, forests, waterways, oceans and the air."

(Durie, 2004. p.4)

My GradDipProfPrac inquiry expressed a number of organisational concepts that I feel are emergent in the Pākehā psyche, informed by the organisational qualities of living systems, that might support ecologically harmonious organisation. The concepts emerging in the Pākehā mindset include an awareness of the world as a web of interconnected systems; self-organisation and decentralisation; collaborative ecologies; the story of interbeing and much more. As this inquiry continues, I am interested in exploring ways these ideas manifest in the organisational patterns of cultures that have embodied them for many generations.

"Through engaging whakapapa, relationships cease to be viewed as simple, binary and linear, instead transforming into complex, layered and fundamentally interconnected... Inter and intra-relationships are considered vitally important within the overarching schema of fundamental interconnection that is whakapapa."

(Kent, 20 I I, p.65) 
"Māori view the universe as process, interconnected and bound together by spirit."

(Marsden, 1989, p. 9)

I suggest that there are emerging cultural synergies between Mãori ways of knowing and the shifts in consciousness happening at the edges of Pākehā culture. For example, for Māori the metaphysical awareness of interconnection is rooted in Te Orokohanga [the creation of the world] and integrally embedded in Te Ao Māori (the Māori worldview). This manifests in a deeply engrained cultural ethos of caring, that extends to all aspects of life. In particular, this awareness of interconnection manifests in the kaitiakitanga (guardianship) of Papatuānuku (Earth Mother) and all her children. As the industrial colonial mindset struggles to respond to severe ecological degradation, ancient Māori customs may illuminate a way of interacting with the world around us that could lead to our collective survival.

These emerging cultural synergies may support shared learning and bring us all together on the same waka (voyaging canoe) journeying toward a shared regenerative future.

My approach to exploring these emerging cultural synergies is informed by the interface research work of Mason Durie: "Rather than contesting relative validities, there are an increasing number of indigenous researchers who use the interface between science and indigenous knowledge as a source of inventiveness. They have access to both systems and use the insights and methods of one to enhance the other. In this approach, the focus shifts from proving the superiority of one system over another to identifying opportunities for combining both."

(Durie, 2004, p. 8)

Durie's acknowledgement of the richness of interface zones reminds me of the exceptional abundance that emerges where two ecosystems meet in zones known as ecotones. For example, the ecotone at the edge of forest and prairie exhibits higher biodiversity and energy exchange than the forest alone. Durie's interface research affirms Te Ao Māori and Te Ao Pākehā as unique and equally valid worldviews, and that the spaces of interaction between the two can be generative fields of creativity and learning.

This conceptualisation of interface research has been further affirmed for me by the work of Angus Macfarlane et al. and the He Awa Whiria framework: "He awa whiria (literally, a braided river), presents a process model that attempts to interrogate and integrate Western science and Indigenous Māori models ... The braided-rivers framework is based on the analogy of two streams of knowledge (Western science and Indigenous Māori) becoming interconnected streams by reaching a point of convergence."

(Macfarlane et al, 2015, p. 64).

The He Awa Whiria framework allows us to "shift thinking away from a 'one stream' paradigm, where a mainstream dominant knowledge is considered, along with mātauranga Māori knowledge, to a 'two stream' approach where both knowledge systems have equal status. This approach does not exclude other cultures or worldviews as it also provides a platform for them to be considered and included." (Arago-Kemp \& Hong, 20 I 8, p. 8).

The He Awa Whiria framework affirmed the braided rivers metaphor as the means within this research for expressing the interweaving of worldviews around the world and in Aotearoa New Zealand. "In the model, when [rivers] do converge, the space created is one of learning, not assimilating " (Arago-Kemp \& Hong, 20।8, p. 8).

"Those who have usually occupied the centre space can rediscover a narrative that was rarely hitherto recognised, without having to concede anything from the knowledge systems to which they are accustomed. 
And those who have traditionally occupied the margins can reclaim a space to express their knowledge systems without fear or prejudice "

(Macfarlane et al, 2015, p. 64).

Learning more deeply of the oppression of indigenous histories and different ways of knowing has shaped this research in every way. In light of my cultural context and conditioning, I have been able to recognise the way my approach to research and writing embodies many colonial norms. Much of my psyche has been shaped and fragmented by the scientific way of knowing the world. I recognise that much of what I thought I knew of social organisation has been framed by Western theory. I have been able to begin the process of challenging my deepseated biases around methodology and the way information could be offered to the world.

This awareness is enabling me to suspend my way of knowing. It is empowering me to listen in a different way. In doing so, I hope to nurture the evolution of cultural intelligence in myself and all those who are exposed to the processes of my inquiry.

"Cultural intelligence is more than the ability to be able to understand and interpret knowledge from within one's own cultural worldview. It is also the ability to articulate, interpret and translate particular knowledge at the interface of other cultures and knowledge systems. Cultural intelligence includes the ability to cross the borders and boundaries of other cultures or of those that are different from your own "

(Arago-Kemp \& Hong, 2018, p. 21).

I consider the survival of the human species to be dependent on this capacity to cross the ambiguous borders of ones own culture with authenticity, humility and a willingness to learn. Without nurturing this capacity in our processes of social organisation we may never be able to live in deep relationship with each other and the world around us.

This acceptance at a deep level allows for all rivers of knowing and being to flow freely - not to the detriment of our own rivers, but to the uplifting of them all.

"[R]esearch and the production of knowledge have been used as a colonial tool to enforce and maintain the cultural superiority of the colonisers, positing Māori as inferior... Linda Tuhiwai Smith remarks that research has been a process that has dehumanised Māori and denied the legitimacy of Māori language, culture and knowledge." (Murphy, 20I I, p. 14). "Categorisation and compartmentalisation of indigenous governance or any other indigenous field, runs real risks of tacit intellectual hegemony, despite researchers best intentions."

(Kent, 201 I, p. 35)

To avoid imposing my cultural biases and perpetuating a legacy of colonial research, I am deepening my engagement as an active participant in bicultural healing. This is not a study of Māori, rather this is an exploration of the relationships in between Māori and Pākehā in Aotearoa - a relationship that I am an active participant in. What emerges will be a story of many stories. It won't read like this article, which still trends towards academic compliance. This article marks my departure from colonial convention. I began this departure throughout my GDPP, but anyone who reads it will still recognise it as an artifact of the ivory tower. As a participant in the movement of indigenous and radical academics seeking pedagogical justice, I am committed to pushing the edges of academia and supporting the transformation of Aotearoa's learning landscape. 


\section{This marks the beginning of a weaving. Of stories.}

"Stories serve to connect the past with the future, one generation with the other, the land with the people and the people with the story."

(Smith, 1999, p. 145).

Stories are awa [rivers] that wind through time, moving meaning between human heartminds. They're the substance of perception, the enabler of learning.

\section{They're the ever-changing manifestation of sapience.}

Stories are human. They are how we create meaning and share that with each other. They surround us, and inform the way our social dynamics work in different contexts. They are the foundations of our organisational patterns. Stories extend far beyond books and oral weavings around the fire. They permeate our lives, influencing our daily behaviour.We gather around stories and build communities. Cultural concepts and social norms, expressed through daily re-tellings, shape the way we interact with each other and the world around us.

$$
\begin{gathered}
\text { Stories shift and twist through time. } \\
\text { They're our expression of reality. } \\
\text { They're our dreams. } \\
\text { They're our wisdom. } \\
\text { They're our way of knowing. }
\end{gathered}
$$

We tell them to each other. We tell them to ourselves.

They feed our subconscious and our collective conscious.

They are the whāriki (woven mat) of human understanding.

"We need stories of sufficient power and complexity to orient people for effective action to overcome environmental problems... to reveal what the possibilities are for transforming these and to reveal to people the role that they can play in this project."

(O'Sullivan, 1999. p. 182).

To honour the significance of pūrakau, storyweaving is both methodology and communication form in this inquiry. Through complex and powerful storytelling, I will weave a story that explores the nuances of social organisation in Aotearoa New Zealand. I will weave old stories and new stories - shared by storytellers around the motu - with my own story. The stories of atua, gods, humans, dreams, flora and fauna will twist and entwine, expressing nuances of social relationships that are not as adequately expressed through academic script.

Te Ao Māori and Te Ao Pākehā are each complex entanglements of diverse people and ideas, woven through time and space. They are integrally and inextricably intertwined with each other. 


\section{The future is shared.}

My intention is that this story will speak to the hearts of all people and will shift ways of thinking, feeling, doing and being. My hope is that in some small way it will help us adapt in response to the crises we face together.

\section{Let us meet where the rivers braid \\ To give and to receive, with honour, The abundance of our kete.}

\section{Nāku tō rourou, nau te rourou, ka ora ai te iwi}

With your basket and my basket the people will prosper

David Hurshouse is an ecological designer, educator, facilitator and activist. He is an integral part of Tuia Learning Environment, and the Chairperson of Permaculture in New Zealand. In these contexts, he is focused on transforming the way individuals and organisations learn in Aotearoa New Zealand. David is enthusiastically supporting change-makers developing human systems more in tune with wider ecological patterns. He moves through the edge-spaces of many worlds, including academia where he is currently engaged in a Doctorate of Professional Practice at Otago Polytechnic.

\section{REFERENCES}

Arago-Kemp,V. and Hong, B. (20 I). Bridging cultural perspectives. Social Policy Evaluation and Research Unit.

Brock, D. (2017). Change Here Now: Permaculture Solutions for Personal and Community Transformation. Berkley: North Atlantic Books.

Durie, M. (2004). Exploring the Interface Between Science and Indigenous Knowledge. 5th APEC Research and Development Leaders Forum.

Kent, S. (20 I I). The Connected Space of Māori Governance:Towards an Indigenous Conceptual Understanding (Pf.D). Lincoln University. Macfarlane, A., Macfarlane, S. and Gillon, G. (20I5). Sharing the food baskets of knowledge: Creating space for a blending of stream. In: A. Macfarlane, S. Macfarlane and M. Webber, ed., Sociocultural Realities: Exploring New Horizons. Christchurch: Canterbury University Press.

Marsden, M. (1989). The natural world and natural resources. Māori values systems and perspectives. Resource management law reform. Working paper no' 29. Part A. Wellington: Ministry for the Environment.

O'Sullivan, E. (1999). Transformative Learning - Educational Vision for the 21 st Century. London: Zed Books.

Pihama, L. (200 I). Tāhei Mauri Ora: Honouring OurVoices - Mana Wahine as a Kaupapa Māori theoretical framework (Ph.D). University of Auckland.

Smith, L. (1999). Decolonizing Methodologies: Research and Indigenous Peoples. Dunedin: University of Otago Press.

Wilmer, F. (1999). Medicine as Metaphor: Indigenous Philosophies of Power. Paper presented at the Global Century/Local Century: Conflict, Communication, Civility Conference, Amsterdam. 